University of Wollongong

Research Online

2013

The promotion of domestic grid-connected photovoltaic electricity production through social learning

Greg Hampton

University of Wollongong, gregh@uow.edu.au

Simon Eckermann

University of Wollongong, seckerma@uow.edu.au

Follow this and additional works at: https://ro.uow.edu.au/ahsri

Research Online is the open access institutional repository for the University of Wollongong. For further information contact the UOW Library: research-pubs@uow.edu.au 


\title{
The promotion of domestic grid-connected photovoltaic electricity production through social learning
}

\author{
Abstract \\ Background: An effective social learning process which enhances public understanding of photovoltaic \\ installations in residential dwellings and the economic instruments used by governments to encourage \\ investment in this form of energy is regarded as an important component of implementing renewable \\ energy policy in Australia. \\ Methods: The development of social learning was explored in deliberative workshops conducted in 2005 \\ and 2012 in New South Wales, Australia. Participants had informed discussion of the operation of \\ photovoltaic panels and how such panels could be integrated into domestic building structure and the \\ economic instruments used by their State and Federal governments to encourage the installation of grid- \\ connected photovoltaic systems. Their attitudes to the technology and investment were surveyed at the \\ end of the workshops. \\ Results: The participants expressed favourable attitudes toward the design, reliability and environmental \\ benefits of such technology and positive attitudes towards the building integration of such panels. \\ However, despite this, the participants were unwilling to invest in this technology, primarily because in \\ 2005 they perceived the financial benefits of doing so as being marginal and in 2012 they were framing \\ investment decisions in terms of reductions in tariff rates since 2010 rather than current returns. \\ Conclusions: Social learning principles can provide a range of benefits for communication and decision \\ making in the informed promotion of grid-connected photovoltaic technology. Public perceptions and \\ citizens' investment decisions should move beyond framing decisions relative to subsidy levels to \\ consider long-term investment returns. Retailers and installers of residential photovoltaic systems in \\ Australia are encouraged to promote the option of building-integrated panels given favourable \\ preferences shown for such technology.
}

\section{Keywords}

grid, connected, promotion, domestic, photovoltaic, learning, electricity, production, social

\section{Publication Details}

G. Hampton \& S. Eckermann, "The promotion of domestic grid-connected photovoltaic electricity production through social learning", Energy, Sustainability and Society 31 (2013) 1-12. 


\title{
The promotion of domestic grid-connected photovoltaic electricity production through social learning
}

\author{
Greg Hampton ${ }^{1 *}$ and Simon Eckermann ${ }^{2}$
}

\begin{abstract}
Background: An effective social learning process which enhances public understanding of photovoltaic installations in residential dwellings and the economic instruments used by governments to encourage investment in this form of energy is regarded as an important component of implementing renewable energy policy in Australia.
\end{abstract}

Methods: The development of social learning was explored in deliberative workshops conducted in 2005 and 2012 in New South Wales, Australia. Participants had informed discussion of the operation of photovoltaic panels and how such panels could be integrated into domestic building structure and the economic instruments used by their State and Federal governments to encourage the installation of grid-connected photovoltaic systems. Their attitudes to the technology and investment were surveyed at the end of the workshops.

Results: The participants expressed favourable attitudes toward the design, reliability and environmental benefits of such technology and positive attitudes towards the building integration of such panels. However, despite this, the participants were unwilling to invest in this technology, primarily because in 2005 they perceived the financial benefits of doing so as being marginal and in 2012 they were framing investment decisions in terms of reductions in tariff rates since 2010 rather than current returns.

Conclusions: Social learning principles can provide a range of benefits for communication and decision making in the informed promotion of grid-connected photovoltaic technology. Public perceptions and citizens' investment decisions should move beyond framing decisions relative to subsidy levels to consider long-term investment returns. Retailers and installers of residential photovoltaic systems in Australia are encouraged to promote the option of building-integrated panels given favourable preferences shown for such technology.

Keywords: Grid-connected photovoltaics; Building-integrated photovoltaic panels; Renewable energy and economic instruments

\section{Background}

Public understanding and policy context of gridconnected photovoltaic electricity production in Australia Use of grid-connected photovoltaics (GCPV), which involve the installation of photovoltaic panels (PV) on a roof or external wall and generating electricity for use and/or export to the grid, has been in its infancy in Australia. GCPV is a renewable source of power without

\footnotetext{
* Correspondence: gregh@uow.edu.au

${ }^{1}$ Academic Services Division, University of Wollongong, New South Wales 2522, Australia

Full list of author information is available at the end of the article
}

environmental cost in producing electricity once installed or the need for land to be used and has minimal transmission or distribution cost [1], while having up front panel, inverter and instillation costs. Much of Australia has an ideal climate for generating solar energy with these technologies, as well as wind energy, and policy support by Governments in Australia for use of renewable energy has emerged over the last 5 to 10 years in large part in response to international targets for greenhouse gas emissions. Production of electricity in Australia has historically been predominantly from burning coal, and Australia retains a very high per capita

\section{实}


emission of greenhouse gases. Government policy to increase use of renewable solar energy generation has been enacted with economic instruments such as rebates and gross feed in tariffs by Federal and State levels of government (electricity grids between states are not fully interconnected nationally). However, there has been meagre research on public familiarity and attitudes towards GCPV and the associated subsidies and feed in tariffs.

This article considers processes of social learning about the economic instruments and decision making, given technology and installation options for photovoltaic electricity production. Empirically, we report on social learning with randomly selected public participants from a regional area south of Sydney, New South Wales in deliberative workshops undertaken at the University of Wollongong in 2005 and 2012. These workshops provided participants with a general introduction to the practical and financial feasibility of domestic production of electricity through installing photovoltaic panels with inverters and the economic instruments involved in residential installation.

The enhancement of social learning about residential photovoltaic installation is an important component of effective policy implementation for renewable energy in the Australian context. Meeting renewable energy targets is in part dependent on citizen take up of renewable energy systems, while it has been left to citizens to initiate the implementation of this technology through a renewable energy certificate system.

Large-scale Generation Certificates are currently provided by the Australian Federal government for the installation of capital equipment in large schemes [2], and as the name suggests, this is likely to be implemented by large-scale generators. Under a parallel small-scale renewable energy scheme, Small-scale Technology Certificates (STC) are provided for domestic installations [3], and it is in this area that citizen social learning is of importance.

This paper considers how social learning processes could be used by such citizenry to aid information flows, decision making and policy implementation. Having set the Australian context for decision making by citizenry in this introduction, the next section considers the decision to invest in PV technology. The concept of social learning in relation to decision making for small-scale $\mathrm{PV}$ investment is then reviewed in relation to technology characteristics (PV system installed costs, expected performance, aesthetics, building integration) and government policy instruments (subsidies, tariffs and rebates) and their interaction in informing expected return on investment, before describing methods for and reporting on attitudes to PV decision making emerging from deliberative social learning workshops run in 2005 and 2012. Finally, the results from the workshops in relation to understanding and attitudes reported are discussed in relation to the differences in policy context and framing of PV investment decisions in 2005 and 2012, drawing out lessons for future policy and use of social learning methods.

\section{Citizenry decisions to invest in PV under alternate policies}

A decision to invest in installing a small-scale photovoltaic installation depends upon the inclinations of residents and their level of knowledge of photovoltaic technology, particularly the relative environmental and economic costs and benefits which may accrue from such installation. An STC can be transferred to and redeemed by a photovoltaic installer, reducing the capital investment costs of a typical 1.5-kilowatt (kW) installation to around Australia $\$ 3,000$ at the time of the workshops in early 2012.

This system of STCs was preceded by a Federal government rebate scheme between 2000 and 2009 which resulted in the installation of 107,572 units generating 128 megawatt (MW) [4]. The previous program has been regarded as being ineffective environmentally and inefficient in terms of failing to promote understanding and acceptance of residential photovoltaic installation. The suggestion is it would have been less costly to employ other strategies such as standard social marketing [4]. Further, such alternative strategies could have mitigated negative publicity and associated framing of investment decisions for residential photovoltaic installation when prices for STCs or State arrangements for feed in tariffs for generated electricity changed in 2010. This, consequently, could also have mitigated the uncertainty and boom and bust cycles for associated manufacturing and installation industries.

Wustenhagen et al. [5] reviewed research on the social acceptance of wind energy and pose some questions which might also arise for citizens who install photovoltaic systems in their residences. Much of the research which has been conducted on social acceptance and renewable energy has been related to wind energy, nuclear power and geothermal, and has not focussed on photovoltaic panels on residences. For example, social acceptance of wind energy has shown the type of landscape to be a critical factor [6]. Analogously, the siting of PV solar panels may be an important issue, particularly if largescale photovoltaic installations become more plentiful. There is some evidence that the visual intrusion of residential panels is associated with a decision not to install panels [7]. Australians may have concerns about the visual amenity of having panels installed on a residence, in relation to which the workshops developed for the current project assessed perceptions of traditional panels versus building-integrated panels. 
There are likely to be varying levels of community engagement and education to promote the installation of a residential photovoltaic system, depending on factors such as whether or not citizens were residents in one of the designated seven Solar Cities in Australia [8]. Education of citizens in general about photovoltaic technology in Australia consists currently primarily of static website information. There have been no apparent government initiatives for citizens to pursue this information or highlight the expected financial returns from investing in and using electricity generated by residential photovoltaic systems.

Assessing citizen attitudes towards and motivation to investing in PV systems in Australia needs to distinguish between wholesale price levels for exported feed in tariffs, effective electricity cost offsets with direct generated use and government subsidized tariffs. Such subsidies can provide incentives to install domestic photovoltaic electricity generation technology but in turn need to consider the real expected return and payback periods given the expected performance, and up front capital costs, of systems.

In addition to Commonwealth Government cost offsets accruing from STCs, State governments across Australia have provided a range of domestic electricity offset and feed in tariff arrangements and associated incentives. These initially ranged from State tariffs with typical small-scale (less than 10-kW systems) systems for net export of electricity in excess of domestic use into the grid (South Australia (SA), Victoria (Vic), Western Australia (WA), Queensland (QLD)) of amounts varying from Australian \$0.44 to Australian $\$ 0.60 / \mathrm{kWh}$ over 10 to 20 years, to gross feed in tariffs in New South Wales (NSW) and the Australian Capital Territory (ACT) over 6 to 20 years from Australian $\$ .040$ up to Australian $\$ 0.60 / \mathrm{kWh}$ [9]. In NSW, where our study is based, an Australian $\$ 0.60$ gross feed in tariff applied to installation and supply agreements in NSW signed from 9 November 2009 up to midnight 27 October 2010 for electricity generated by PV panels up to 31 December 2016 under the Solar Bonus Scheme program. This program essentially covered the capital investment costs by households of a typical $1.5-\mathrm{kW}$ system installation (around Australian \$6,000 during 2010) by the end of 2016, given that under this tariff such a system reduces energy costs or generates income of approximately Australian \$1,100/year. This NSW program has more recently been framed as burdensome by the current NSW State Government, but the program did ensure a rapid uptake of photovoltaic technology in the State, while not committing tariff funding beyond 2016 unlike other state schemes. For agreements signed after the 28 October 2010, the gross feed in tariff in NSW was reduced from Australian $\$ 0.60 / \mathrm{kWh}$ generated to
Australian $\$ 0.20 / \mathrm{kWh}$, but a newly elected state government in April 2011 effectively removed any government subsidy, moving to a tariff to reflect the cost of undistributed wholesale electricity. For PV panel installation and supply agreements in New South Wales at the time of the workshops conducted in 2012, residents could receive around an average Australian $\$ 0.07 / \mathrm{kWh}$ for electricity exported to the grid - a price which is based on the spot price which a wholesaler would receive for electricity generated in the state [10]. Alternatively, if the residents in NSW were to utilize electricity generated by their photovoltaic installation in their own home, this would be financially equivalent to what they would pay for utilizing electricity from the grid, typically Australian $\$ 0.22$ to Australian $\$ 0.24 / \mathrm{kWh}$, unless use is off-peak. Hence, offsetting domestic use in peak periods when PV electricity is generated would, on average, provide three times the price which they are offered for exporting electricity through a net feed in tariff. However, to utilize PV energy generated at their home, residents would have to utilize this electricity at the time it is generated (during sunlight hours) which may not be feasible for many residents given their patterns of energy consumption.

Extensive publicity and political attention around the reduction in gross feed in tariff rate to Australian \$0.20/ kWh for systems signed off after the 27 October 2010, and further falls in the exporting rate when investing beyond 28 April 2011, has negatively framed public perception of investing in domestic photovoltaic technology in NSW after 27 October 2010. Indeed, beyond 28 April 2011, while the Independent Pricing and Regulatory Tribunal (IPART) recommended a non-mandatory price per $\mathrm{kWh}$ around the wholesale average undistributed price of Australian $\$ 0.052$ to Australian $\$ 0.103$ per kWh in 2011 to 2012 and Australian \$0.077 to Australian $\$ 0.129$ in 2012 to $2013[11,12]$, electricity retailers effectively paid at the bottom of these ranges, if anything, for PV exported electricity. Hence, there was marginal if any return received from investing in a gross metered system, depending on retailer after 28 April 2011, with net meters clearly preferable when offsetting domestic electricity use with PV energy generated during daylight hours (effectively Australian \$0.20 to Australian \$0.28, depending on provider over 2011 to 2013).

Importantly, the rate of payment for PV energy generation with investment after 27 October 2010 was publicly framed as a loss relative to that previously received at Australian $\$ 0.60 \mathrm{c} / \mathrm{kWh}$. Public framing and focus on such perceived losses is, following prospect theory and loss aversion with higher valuing of perceived losses than gains [13], expected to lead to sharp falls in GCPV investment and installations. However, continual significant decreases in capital costs faced by households for installing systems after 27 October 2010 and increasing 
prices for grid electricity mean that while the payback period for installing domestic solar panels may have increased somewhat, the long-term rate of return to households on a typical $1.5-\mathrm{kW}$ system has in fact increased over time. For example, a reduction for the installed cost to a household of a $1.5-\mathrm{kW}$ system to $\$ 3.000$ with an agreement signed in early 2011 , with an Australian $\$ 0.20$ c feed in tariff until the end of 2016, results in an expected 7- to 9-year payback period. A 1- to 3-year payback period beyond 2016 depending on the extent to which feed in tariffs are higher than Australian $\$ 0.30$ beyond 2016 , with converting from gross to net meters and domestic generation offsets daylight consumption and doubles the return on initial capital investment relative to an Australian $\$ 6,000$ system beyond that. Hence, falls in capital costs after October 272010 result in a higher rate of expected overall investment return with an outlook beyond 10 to 15 years despite the lower rate of tariff to 31 December 2016 in NSW. Indeed, the long-term return continues to rise with continuing falls in capital costs of installation, even with the further fall in effective gross tariffs paid to the end of 2016. Currently, 1.5-kW systems in NSW installed with net meters offset energy use during daylight (about Australian $\$ 0.25$ to Australian $\$ 0.30 / \mathrm{kWh}$ ) and receiving what amounts to an average wholesale price (around Australian $\$ 0.077 / \mathrm{kWh}$ ) with an appropriate choice of retailer can be installed for as little as Australian \$1,500. This results in a 4- to 12-year payback period, depending on energy use offset and the extent to which the retail and wholesale price for electricity can be expected to increase to 2016 and beyond. If, as reported by IPART, on average, two thirds of PV generation is consumed and one third exported to the grid, then the average payback period with a net meter and $1.5-\mathrm{kW}$ system in 2013 would be approximately 6 to 7 years, depending on the rate of increase in electricity prices [12]. Those consuming all PV energy generated would have a payback period of approximately 4 years, those who export $50 \%$ about 9 years, and those exporting all energy generated around 12 years.

Beyond 2016, the net-metered PV systems with Australian $\$ 1,500$ capital installation costs in 2013 will have twice the return on capital of fixed systems installed for Australian $\$ 3,000$ and four times the return on a system installed for Australian $\$ 6,000$ in 2010. Those with a gross feed in meter who received Australian $\$ 0.60$ and Australian $\$ 0.20$ will also face costs of converting to a net meter post 2016 to allow for the higher effective returns from offsetting electricity use during PV generating hours.

Consequently, the processes of social learning and the investigation of public perceptions is becoming increasingly pertinent to effective promotion, informed investment decisions and efficient implementation of such domestic PV systems in NSW. Further, while the above consideration of returns on investment is framed in the context of subsidized gross-metered tariffs in NSW, similar calculations and arguments for approaches to informed promotion with social learning apply in other jurisdictions (Australian States and elsewhere) where reduced capital costs and increasing energy prices result in increased long-term return on investment for net-metered PV systems despite removal of previously subsidized tariffs for fixed periods. However, despite the general and increasing need to have informed public perception and investment decisions, the promotion of domestic utilization of photovoltaic technology in Australia remains very limited. This is primarily limited to Internet websites created by government departments and installers of photovoltaic panels and occasional printed postal information provided by utilities and retailers.

It is suggested that in order for citizens to be more knowledgeable about the environmental and financial returns from installing photovoltaic technology, consideration should be given to the utilization of processes of social learning within various modes of educating citizens. These processes of social learning can be incorporated in community information sessions and other forms of media promotion.

\section{Social learning}

Social learning is briefly reviewed to articulate essential components required for a social learning process in relation to domestic grid-connected photovoltaic systems. The facilitation of social learning is critical to the process of developing citizen proficiency in understanding science and technology. It is designed 'to enlarge the citizen client's abilities to pose the problems and questions that interest and concern them and to help connect them to the kinds of information and resources needed to help them find answers' [14]. Schusler et al. ([15], p. 311) defined social learning 'as learning that occurs when people engage one another, sharing diverse perspectives and experiences to develop a common framework of understanding and basis for joint action'. Keen et al. [16] propose a model of social learning comprised of reflection, systems orientation, integration, negotiation and participation. They include the economic system in their system orientation which is relevant to financial aspects of the installation of gridconnected photovoltaic production of electricity in domestic premises.

In social learning, the social condition can be changed or altered, especially changes in how one perceives their personal interests compared to and connected with the shared interests of their community [17]. Conditions for 
social learning need to be conducive for meaningful dialogue and interaction to occur between experts and non-experts that results in an environment for thinking and learning together. Some aspects of a program that can promote social learning include providing an atmosphere of open dialogue and transparency of information, opportunities for repeated meetings and gatherings, access to expert support, face-to-face small group work, site visits and tours, unrestricted opportunities to influence the program process and political support for the process [17]. In this project, we developed a deliberative workshop format which provided participants with information on photovoltaic technology, building integration of photovoltaic technology, government economic instruments designed to promote domestic use of this technology and the opportunity to reflect on this information.

The sharing of diverse participant perspectives involves providing a public with an opportunity to discuss their experience and local knowledge of an issue [14]. Local knowledge is often tacit knowledge which can be rendered explicit through deliberation $[18,19]$. In the deliberative workshops, we built upon participants' local knowledge by referring to other forms of renewable energy, already in existence in the local area, which they were familiar with and provided participants with the opportunity to elaborate on the issues which arose for them in the workshops.

Deliberative workshops incorporating social learning provide the opportunity for participants to consider technological and domestic issues in depth as well as elicit issues not considered by researchers. The workshops provided participants with an opportunity to share their views on energy production and individual usage and the personal, economic and social conditions which influence the uptake of photovoltaic systems in domestic dwellings. The participants were provided with opportunities to discuss similar technologies, such as wind energy and a local trial of ocean tidal generation of electricity, which informed their understanding of similar contexts for photovoltaic electricity production. In order to develop the workshop process, social science research relevant to citizen attitudes towards and knowledge of photovoltaic technology was reviewed. This guided the choice of relevant content for the development of the workshop process, highlighting aspects of public understanding of residential photovoltaic technology.

\section{Previous studies of motivational and attitudinal factors associated with residential grid-connected photovoltaic technology}

Studies of understanding and attitudes to domestic installations of grid-connected photovoltaic systems have largely been conducted in Europe and America, and generally show that citizens have positive attitudes towards GCPV [20]. Some populations while having a positive attitude towards GCPV tended to confuse such installations with roof-mounted solar hot water [21]. However, only a small proportion of a population are prepared to invest in such technology. Oppenheim [22] refers to $1 \%$ of consumers in two American cities being willing to pay extra to have photovoltaic panels on their roof. Faier and Neame [7] note the lack of uptake of a combined photovoltaic and thermal solar panel system made available in England under a grant system that provided $50 \%$ of the installed capital cost.

\section{Building integration of photovoltaics}

Building-integrated photovoltaic panels do not feature extensively in installations in Australia, whereas they do in the northern hemisphere. Social research on this aspect of photovoltaic technology is limited, with Sylvester [23] having studied simulation of photovoltaic filtering on windows in office buildings. Although the participants were in favour of the energy and associated energy cost savings of this technology, they were dissatisfied with the disruption to natural light in the building. Blewett-Silcock [24] studied public reactions to buildingintegrated photovoltaic technology in an English university. He examined whether participants found the materials attractive and found that this depended on the type of building they were asked to evaluate. Interestingly, the participants did not link the electricity they used in the office with that generated by the façade.

\section{Perceived economic feasibility}

Perez et al. [25] consider the perception of economic feasibility of photovoltaic electricity generation and solar hot water production. Initially, they considered shortterm payback, the net cost divided by the first year energy cost savings, but quickly dismiss this as too simple and partial, in failing to take account long-term impacts of GCPV. Long-term return requires assessing the net present value (NPV) - the economic value over a product's lifetime, where they demonstrated a positive value. Importantly, in assessing NPV, they highlighted that current retail costs do not reflect some of the advantages of GCPV with dispersed production of electricity on site rather than undispersed electricity, the value of which they estimated as US\$0.01 to US\$0.06 more per $\mathrm{kWh}$. Hence, comparisons with other technologies should compare the NPV of lifetime distribution costs. Similarly, Riedy [26] notes that, in general, transmission pricing regimes in Australia are biased against distributed generation such as GCPV while favouring undistributed generation such as coal fire production. Distributed generation sources such as GCPV should not be compared as though they use the transmission system. 


\section{Feed in tariff}

Wiginton et al. [27] argue that feed in tariffs have been the most effective government incentive program for encouraging domestic photovoltaic installation, and those countries which have introduced feed in tariffs have seen the greatest uptake. Mitchell et al. [28] maintained that the German feed in tariff scheme is more effective at increasing the share of renewables than the Renewables Obligation in England and Wales because it reduces risk more effectively for generators; such arguments are reiterated by Lesser and $\mathrm{Su}$ [29]. Schaefer et al. [30] reported favourable citizen attitudes towards feed in tariffs in a survey of views on domestic wind energy production in New Zealand and refer to similar findings in Canada and Japan. Maine and Chapman [31] demonstrated that during industry infancy, paying the spot price for electricity in South Australia provided insufficient incentive to take up solar electricity, suggesting that it was an unsuitable base on which to formulate a feed in tariff to promote PV installation.

\section{Rebates and subsidies}

Haas et al. [32] have examined participants' motives in the Austrian rooftop program of the early 1990s and found that the rebate was an essential factor in the adoption of GCPV for $40 \%$ of participants. About 35\% of participants would have purchased a system without a rebate. Haas et al. [32] regarded the high investment costs as a major barrier for broader market penetration. They noted a high willingness to pay for photovoltaics, which is above the level of cost-effectiveness but argued that this willingness is dependent upon rebates or other financial incentives. Haas [33] argued that rebates are an effective tool in expanding photovoltaic markets but that the rebates in almost all programs are too high and do not provide a sufficient incentive for a customer to find the most efficient system. Hence, while they may be appropriate for an early stage of market diffusion, rate-based incentives are the most effective tool for efficiently increasing GPCV use.

\section{Chosen features for a social learning and attitude evaluation process for GCPV in NSW}

The review of social science studies relevant to GCPV in NSW suggests that a relevant social learning and attitude evaluation process should

- discuss and demonstrate how domestic installations operate and assess participants' attitudes to GCPV and willingness to pay to have an installation in their residence;

- provide information and assess understanding of the economic and environmental impacts of distributed generation and evaluate participants' attitudes towards such impacts;
- evaluate participants' attitudes to the design and appearance of building-integrated panels;

- provide explanations on the operation of feed in rates in New South Wales, provide comparisons with other States in Australia and assess participants' attitudes towards and preferences for levels of feed in rates;

- provide information on the types of rebate that have been made available by the Federal government in Australia and assess participants' attitudes towards and preferences for rebates provided.

These content and evaluation areas were incorporated in the development of a deliberative workshop process.

\section{Methods}

\section{Deliberative workshop method}

Four deliberative workshops were conducted with citizens in the Illawarra region of New South Wales, Australia, implementing a social learning method for developing and assessing public understanding of residential photovoltaic installations. The participants were systematically selected [34] from the local telephone directory and paid Australian \$50 for their participation in a 90-min workshop. The workshop was conducted with the aid of a PowerPoint audiovisual presentation, which included information about how photovoltaic panels operated and images of photovoltaic panels utilized in domestic installations. The participants were provided with a booklet which had a printed version of the slides contained in the audiovisual presentation.

The workshop commenced with a discussion of renewable energy and the various means by which it can be produced. This focused on the generation of electricity through wind turbines and a local system which utilized wave energy. The audiovisual presentation provided information on the basic operation of a photovoltaic panel. It also presented images of the basic installation of panels on a domestic rooftop with traditional mounting of panels on a rack.

The presentation then provided photographs of building-integrated panels which are more prevalent in Japan and Europe. The participants were asked to rate the attractiveness and design of four building-integrated types of panels and four non-integrated types of panels on 10-point semantic differential scales, where 1 was attractive and 10 unattractive; and on a second semantic differential, where 1 was not well designed and 10 was well designed. These different types of panels were represented by computer graphics which presented different types of generic panel structures. These included nonintegrated panels on two upright short racks, panels on four long flat racks, flat panels on tiles; and integrated panels on short skylights, elongated skylights, panels 
which completely replace roof tiles and look like a flat iron roof, and panels which completely replace traditional roof tiles and look like roof tiles.

The presentation then focused on the financial aspects of installing panels on a domestic dwelling and the rebates which were available from the Federal government. In 2005, the Federal Government provided a rebate of Australian $\$ 7,920$ for the installation of 1.5 $\mathrm{kWh}$ of panels (usually six panels), which typically cost Australian $\$ 14,000$ to install, thus requiring an outlay of Australian $\$ 6,080$. The state governments would typically pay for electricity generated, which was excess to domestic usage, at the same rate at which they sold electricity to residents, usually at Australian $\$ 0.125 / \mathrm{kWh}$. The participants were told that this size of installation would typically generate $1,461 \mathrm{kWh}$ of electricity per annum which would be worth Australian $\$ 4,566$ over a 25-year period, the expected life of the panels. The scenario of a payment of Australian \$.50/kWh was also discussed. This feed in rate was available in Germany and was being considered for the Northern Territory in Australia. They were also told that the maintenance cost of the panels would typically be Australian $\$ 650$ for the purchase of a new inverter, which might become necessary at some stage of the expected 25-year life of the panels.

The participants in 2012 were told that a $1.5-\mathrm{kWh}$ system would cost Australian $\$ 7,000$ and there would be a government rebate in the form of a renewable energy certificate with a solar credit of Australian \$3,720 which the supplier via the resident would receive, leaving a resident to pay Australian \$3,280. They were told that if they used the electricity generated, depending on the tariff they paid for electricity from the grid, it would be expected to be worth Australian \$300/year at Australian $\$ 0.20 / \mathrm{kWh}$ or Australian $\$ 7,500$ over the expected 25year operation of the panels, assuming electricity prices increase at the same rate as inflation. They were also told that this may not be feasible, as for it to be worth this amount, they would have to use energy during daylight hours, when it was generated. If they fed it back to the grid, then under proposed arrangements, they would receive about Australian $\$ 0.077 / \mathrm{kWh}$, the wholesale undistributed price to be paid for electricity generated by $\mathrm{PV}$ in NSW. They were also told that the maintenance costs for a set of panels would typically be Australian $\$ 650$ for the purchase of a new inverter at some stage of the expected 25-year working life of the panels.

The participants were finally asked to complete a questionnaire in which they rated their agreement with various attitude statements about photovoltaic panels, on 7-point Likert scales, where 1 indicated very strongly agreeing and 7 was very strongly disagreeing. They were asked to rate whether they considered the panels to be environmentally worthwhile, financially worthwhile, reliable, safe, whether or not panels could be constructed to be unnoticeable on roofs and whether or not they detract from the appearance of a house. They were also asked to rate their intention to install photovoltaic panels on a 4-point scale of very likely to very unlikely. If they were not prepared to install panels, they were asked if they would be prepared to do so if the rebate in 2005 or the solar credit in 2012 was higher and by how much, and if a feed in tariff rate on electricity generated was higher and by how much.

Discussion about the various technological and financial aspects of photovoltaic panels was encouraged in the workshop. Discussion was encouraged through asking the participants what they knew about renewable energy and how important it was to them; whether they had any safety concerns about installing a set of photovoltaic panels on their residence, what they thought of the appearance of integrated and non-integrated photovoltaic panels, what they thought of the financial benefits of installing a set of panels on their residence and whether they thought it was more important to receive a high rebate or feed in tariff.

Bang et al. [35] argue that more qualitative work is needed to ascertain what beliefs people have about renewable energy. The workshop proceedings were recorded, transcribed and qualitatively analysed, but while the quantitative results are reported, the qualitative results are not reported in detail in this particular article.

\section{Research expectations}

Although this was a preliminary study examining how a social learning method could be implemented on residential grid-connected photovoltaics, there were some expectations about the deliberations which ensued even though an initially small sample size was utilized. These expectations were as follows:

- Only a small proportion of the public would be prepared to purchase a set of photovoltaic panels in 2005, and the awareness and understanding of photovoltaic technology would be minimal in the general community.

- A higher proportion of the public would be prepared to purchase a set of photovoltaic panels in 2012, and there would be increased awareness in the local community about the nature of photovoltaic panels and familiarity with such panels partly due to the publicity surrounding the brief implementation of a subsidized gross feed in tariff policy, by the State government, which had been terminated before the 2012 workshops were conducted.

- Positive attitude towards the environmental benefits of photovoltaic panels would be less of a predictor 
of intention to purchase a set of panels than positive attitude towards the financial benefits of purchasing a set of panels.

- A larger proportion of the sample would be prepared to purchase a set of panels if the installed cost was lower and/or rebate in 2005 or solar credit in 2012 and feed in tariff rate was higher.

- The public would have more positive attitudes towards the attractiveness and design considerations of building-integrated panels than traditional panels.

\section{Results}

\section{Analysis of questionnaire responses}

In 2005, seven participants attended the first workshop, and eight participants attended the second workshop. In 2012, seven people attended the third workshop, and nine attended the fourth workshop. The participants comprised approximately half male and half female in each workshop, half of whom were over 45 years of age and predominantly living with a spouse or partner. The participants were from a range of occupational backgrounds with professional and retired categories, having more than five participants in 2005 and 2012. One third of the participants were receiving more than Australian $\$ 80,000$ gross income per year, one fifth were receiving between Australian \$50,000 and Australian \$80,000/year, and one fifth Australian $\$ 40,000$ to Australian $\$ 50,000$ / year. There were no differences in the demographic characteristics of the two samples in 2005 and 2012.

None of the participants in the 2005 sample had purchased a photovoltaic system, whereas one participant had purchased such a system in the 2012 sample. While the mean difference in likelihood of purchasing a system between year of consultation $(2005 M=2.86$, $\mathrm{SD}=0.24$; $2012 M=2.5, \mathrm{SD}=0.22$ ) was not statistically significant $(F(1,30)=1.27, p<.28)$, in 2012 , there was an $88 \%$ increase in the proportion of participants who said that they would be likely or very likely to purchase a photovoltaic system $(8 / 16=50 \%$ vs $4 / 15=27 \%)$. There was a concomitant decrease of $77 \%$ in the proportion of participants (6\% vs $27 . \%$ ) who said that they would be very unlikely to purchase a photovoltaic system in the near future (see Table 1).

Forty percent (6/15) of the 2005 sample stated that they would need to receive Australian $\$ 0.50 / \mathrm{kWh}$, and four participants chose other rates: Australian $\$ 0.20$, Australian \$0.30, Australian \$0.70 and Australian \$1/ $\mathrm{kWh}$, while $33 \%(5 / 15)$ of the participants in 2005 did not respond. In 2012, 38\% participants responded $(6 / 16)$ and were evenly spread over Australian $\$ 0.20$ to Australian $\$ 1.00 / \mathrm{kWh}$, while $62 \%(10 / 16)$ did not respond to this question. The mean difference between year of consultation in preferred feed in tariff rate was not statistically significant $(F(1,15)=0.57, p<.47)$.
Table 1 Frequency of response of participants' likelihood of purchasing a photovoltaic system

\begin{tabular}{lccc}
\hline Response & \multicolumn{2}{c}{ Year } & Total \\
\hline Very likely & $\mathbf{2 0 0 5}$ & $\mathbf{2 0 1 2}$ & \\
Likely & 2 & 1 & 3 \\
Unlikely & 2 & 7 & 9 \\
Very unlikely & 7 & 7 & 14 \\
Total & 4 & 1 & 5 \\
\hline
\end{tabular}

Participants' acceptable capital purchase price for a set of six panels are listed in Table 2. The mean difference in price that participants were prepared to pay for purchase and installation, between year of consultation, was not statistically significant $(F(1,20)=2.69, p<.11)$. The median prices that participants were prepared to pay for the installation of a $1.5-\mathrm{kW}$ system was significantly less in 2012 (Australian \$2,000) compared to 2005 (Australian $\$ 5,000$ ), consistent with a fall in capital cost for installing such systems. There was a large proportion of participants who did not respond to this question in 2012 (9/16), reflecting uncertainty around tariffs and return on investment from capital and the public framing of this decision in light of perceived losses in tariffs relative to earlier investment.

Multivariate analysis of variance indicated a significant multivariate effect due to year of consultation on participants' mean ratings for the general characteristics of photovoltaic panels $(F(7,23)=556.85, p<.001)$. The mean ratings of panels and the significance of the differences in mean ratings by analysis of variance (ANOVA) from 2005 and 2012 are shown in Table 3. The participants in 2012 placed significantly greater emphasis on whether investing in panels was financially worthwhile or not as well as statistically significant greater emphasis on whether panels detract from the appearance of houses.

Table 2 Participants' preferred capital purchase price for a set of six panels

\begin{tabular}{lccc}
\hline Purchase price (Australian \$) & $\mathbf{2 0 0 5}$ & $\mathbf{2 0 1 2}$ & Total \\
\hline 0 & 0 & 1 & 1 \\
500 & 0 & 1 & 1 \\
1,500 & 0 & 1 & 1 \\
2,000 & 2 & 2 & 4 \\
2,500 & 2 & 1 & 3 \\
2,800 & 0 & 1 & 1 \\
3,000 & 1 & 0 & 1 \\
4,500 & 2 & 0 & 2 \\
5,000 & 2 & 0 & 2 \\
6,000 & 4 & 0 & 4 \\
30,000 & 1 & 0 & 1 \\
\hline
\end{tabular}


Table 3 Participants' ratings of the characteristics of photovoltaic panels

\begin{tabular}{|c|c|c|c|c|}
\hline Panel characteristic & 2005 mean ratings (SD) & 2012 mean ratings (SD) & $F(1,29)$ & Probability \\
\hline Environmentally worthwhile & $1.87(1.06)$ & $2.12(0.23)$ & 0.59 & $<.45$ \\
\hline Financially worthwhile & $5.43(0.19)$ & $2.94(0.17)$ & 95.86 & $<.001$ \\
\hline Not financially viable & $3.29(0.32)$ & $4.53(0.29)$ & 8.38 & $<.01$ \\
\hline Reliable & $2.29(0.27)$ & $2.71(.25)$ & 1.29 & $<.27$ \\
\hline Safe & $2.00(0.96)$ & $2.65(0.20)$ & 4.69 & $<.04$ \\
\hline Unnoticeable on roofs & $2.00(0.29)$ & $3.35(0.26)$ & 12.03 & $<.01$ \\
\hline Detract from the appearance of a house & $4.71(0.39)$ & $3.59(0.35)$ & 4.63 & $p<.04$ \\
\hline
\end{tabular}

Ratings of whether or not a grid-connected photovoltaic installation was environmentally worthwhile and financially worthwhile were regressed on ratings of likelihood to purchase a set of panels, in order to assess the relative predictive efficacy of these factors. The regression model was significant $(F(2,30)=4.45, p<.05)$. The likelihood of purchasing a set of panels was predicted by whether participants considered that panels are financially worthwhile and not based on whether they considered such panels to be environmentally worthwhile.

The mean ratings for the attractiveness and design of the integrated panels were that such panels were considered more attractive than non-integrated panels in 2005 and 2012, see Table 4. For the repeated measures ANOVA, there was no main effect for year of consultation or significant interaction between the rating of attractiveness and year of consultation. The integrated panels were also rated as being better designed than the non-integrated panels in 2005 and 2012. Once again, there was no main effect for year of consultation or significant interaction between rating of design and year of consultation.

Although the qualitative analysis of the workshop discussion is not reported here, it is worth noting that some 2005 workshop participants initially misunderstood photovoltaic technology to be solar hot water technology. The participants in the 2012 workshops did not indicate this misunderstanding but were concerned about the safety of installing photovoltaic panels on their roofs, whether such panels were a fire hazard and whether they would withstand storm damage. The qualitative data obtained in the workshops provide details of the social learning process which occurred. Briefly, the participants shared their knowledge of renewable energy, which was primarily solar hot water in 2005. Through discussing the difference between solar hot water production and photovoltaic electricity production, the participants shared and developed their understanding of the differences between these two forms of renewable energy. There was considerably more understanding of the operation of photovoltaic panels in 2012, and the participants were fairly conversant with the operation of such technology. Social learning also took place with regard to the building integration of photovoltaic panels. There was considerable discussion about how this type of photovoltaic panels was preferable to stand-alone panels in 2005 and 2012 in terms of the aesthetic benefits and in terms of the monetary benefits of substituting photovoltaic panels for building materials. The participants' understanding of the financial costs and benefits of GCPV also benefited from a social learning process, whereby participants shared their understanding of feed in tariffs and how they were operating in 2005 and 2012.

\section{Discussion}

The questionnaire results indicate positive attitudes to domestic installation of photovoltaic panels but a reticence to participate in the rebate scheme in existence in 2005 because it was not seen as financially viable. The participants in 2005 were more willing to participate in the scheme if the government rebate had been higher. The participants also felt that the feed in tariff should be higher. The participants in the 2012 workshops were more likely to purchase a set of panels, but the difference with the 2005 participants was not statistically significant.

Table 4 Participants' ratings of the attractiveness and design of building-integrated and non-integrated panels

\begin{tabular}{|c|c|c|c|c|}
\hline Panel characteristic & 2005 mean ratings (SD) & 2012 mean ratings (SD) & $F(1,30)$ & $P$ value \\
\hline Attractiveness of integrated panels & $3.66(1.65)$ & $4.19(1.35)$ & 35.60 & $<.001$ \\
\hline Attractiveness of non-integrated panels & $5.51(1.93)$ & $5.47(1.61)$ & & \\
\hline Good design of integrated panels & $8.28(1.07)$ & $6.74(1.43)$ & 34.97 & $<.001$ \\
\hline Good design of non-integrated panels & $5.88(1.96)$ & $5.08(1.25)$ & & \\
\hline
\end{tabular}


Forty percent of the participants in the 2005 workshop $(6 / 15)$ indicated an interest in receiving Australian $\$ 0.50 / \mathrm{kWh}$. This was probably due to a discussion in the 2005 workshops of an Australian \$0.50/kWh hour feed in tariff rate proposed for the Northern Territory in Australia. The participants' preferred feed in tariff was evenly spread between Australian \$0.20 and Australian $\$ 1.00 / \mathrm{kWh}$ for 2012 , while $38 \%$ (6/16) did not respond. This indicates that the participants may not be connecting return on investment to initial investment capital and had difficulty answering the question. There was also a high non-response to how much they were prepared to pay for the purchase of a set of panels (32\% in 2012). Non-responses were not observed for other items in the questionnaire. These questions may be more readily answered through a discrete choice experiment structure [36] which provides a more readily interpreted structure and such a structure will be trialled in future research. The high level of prices that participants were prepared to pay in 2005 (median of Australian \$5,000) than those in 2012 (median of Australian \$2000) is expected given the quoted retail price of Australian \$6,080 when the federal government rebate was taken into account in 2005, whereas in 2012, the general price for a $1.5-\mathrm{kW}$ system was Australian $\$ 3,280$ when solar credits were taken into account.

The participants' ratings of the general characteristics of panels differed significantly between years of consultation. The participants in 2012 had greater agreement than the 2005 participants with the statement that panels are financially worthwhile and disagreed more with the statement that panels are not financially viable. This reflects the significantly lower capital costs of installing systems and despite 36\% lower feed in tariff than in 2005 (Australian $\$ 0.08$ vs Australian $\$ 0.13 \mathrm{c} / \mathrm{kWh}$ ). The participants in 2012 were concerned about the safety aspects of installing photovoltaic panels on a residence. This was reflected in the ratings that participants provided on the characteristics of panels and also in the discussions which took place in the workshops in 2012, where participants were concerned about whether or not the panels could cause a fire or whether or not they would withstand storm damage. This may have been instigated by the reports in the media in the year preceding the 2012 workshops about electrical and fire problems which had arisen through an environmental program in which the installation of house insulation was implemented through a subsidy provided by the Federal Government.

In 2005, the participants' understanding of solar hot water generation was the initial knowledge of parallel phenomena which they brought forth in their discussions about photovoltaic electricity generation. Some participants in 2005 did not initially understand the differences between solar hot water and photovoltaic electricity generation. Knowledge about solar hot water production was what they initially discussed in relation to the topic of the workshop.

Government action, encouraging public action, was also considered important by the participants in 2005 and 2012. In 2005, they considered that the subsidy should be greater to enable more panels to be installed. The participants in 2005 were also in favour of a higher feed in tariff. They considered that they would be more motivated to purchase panels if the feed in rate was higher. The participants in 2012 were still in favour of higher feed in tariffs as would be expected.

The semantic differential ratings of the buildingintegrated panels indicated a positive evaluation of such integration with participants, considering that such panels were more attractive and better designed in both 2005 and 2012. The ratings suggest that retailers should consider marketing and selling such panels as they may significantly enhance the public's interest in and attitude toward such technology.

Discussion in the 2005 workshops indicated misunderstandings in the participants' perceptions of the practicalities of utilizing GCPV technology. If the researchers had relied on their own understandings and knowledge of citizen interpretations of the way in which such technology operates, they would have missed out on various aspects of citizen understanding of photovoltaic technology which were tacit in their understanding of how such technology operates. This indicates the worth of implementing a social learning approach to informing the public about residential grid-connected photovoltaic installation.

Discussion in the 2012 workshops indicated greater understanding of the operation of domestic photovoltaic installations than that in the 2005 workshops. However, the research indicates that the 2012 participants had increasing difficulty expressing their attitudes towards the financial arrangements which are currently in place for residents who wish to install photovoltaic systems in their residences, which likely reflect changes in tariff policy and associated uncertainty. Importantly, such policy changes in NSW appear to have framed public perception of investment in GCPV now as a loss relative to investment when tariffs were Australian $\$ 0.60 \mathrm{c} / \mathrm{kWh}$ until 2016. This is in spite of long-term returns on investment in GCPV in fact being higher as capital costs of installed GCPV systems have significantly fallen and despite NSW pricing not appropriately having taken into account the lower distribution costs of residential GCPV-generated electricity. This research is timely in informing the public and government policy, showing the impacts on decisions to install GCPV technology are in large part dependent on factors which have not been 
considered or researched. Namely, what citizens perceive as reasonable and fair and sufficiently motivating to invest in installing a GCPV system in their residences, how well that is informed and how those factors have been framed and changed over time $[10,12]$.

\section{Conclusions}

Social learning principles can provide a range of benefits for communication and decision making in the informed promotion of grid-connected photovoltaic technology. Public perceptions and citizens' investment decisions should move beyond framing decisions relative to subsidy levels to consider long-term investment returns, which generally continue to improve with falling capital costs and higher energy prices, despite reducing generation subsidies in New South Wales since 2010. Retailers and installers of residential photovoltaic systems in Australia are encouraged to promote the option of building-integrated panels given favourable preferences shown for such technology.

\section{Competing interests}

The authors declare that they have no competing interests.

\section{Authors' contributions}

$\mathrm{GH}$ designed the study and questionnaire, and conducted the statistical analysis. SE provided analysis and commentary on the economic and financial aspects of the study. GH conducted the workshops in 2005 and 2012, and SE contributed to the 2012 workshops. The authors read and approved the final manuscript.

\section{Author details}

${ }^{1}$ Academic Services Division, University of Wollongong, New South Wales 2522, Australia. ${ }^{2}$ Australian Health Services Research Institute, Sydney Business School, University of Wollongong, New South Wales 2522, Australia.

Received: 21 July 2013 Accepted: 1 November 2013

Published: 26 November 2013

\section{References}

1. Bakos GC, Soursos M, Tsagsas NF (2003) Technoeconomic assessment of a building-integrated PV system for electrical energy saving in residential sector. Energ Build 35:757-762

2. Australian Government Clean Energy Regulator (2012a) RET power stations http://ret.cleanenergyregulator.gov.au/For-Industry/RET-Power-Stations/retpower-stations. Accessed 30 Nov 2013

3. Australian Government Clean Energy Regulator (2012b) Renewable energy target. http://www.cleanenergyregulator.gov.au/Renewable-Energy-Target/ Pages/default.aspx. Accessed 1 Jul 2012

4. Macintosh A, Wilkinson D (2011) Searching for public benefits in solar subsidies: a case study on the Australian government's residential photovoltaic rebate program. Energ Policy 39:3199-3209

5. Wustenhagen R, Wolsink M, Burera M (2007) Social acceptance of renewable energy innovation: an introduction to the concept. Energ Policy 35:2683-2691

6. Wolsink M (2007) Planning of renewables schemes: deliberative and fair decision-making on landscape issues instead of reproachful accusations of non-cooperation. Energ Policy 35(5):2692-2704

7. Faiers A, Neame C (2006) Consumer attitudes towards domestic solar power systems. Energ Policy 36:1797-1806

8. Australian Federal Government (2011) Solar Cities: catalyst for change Background paper. http://www.climatechange.gov.au/energy-efficiency/ solar-cities. Accessed 30 Nov 2013
9. Australian Government Clean Energy Regulator (2012c) Renewable energy target: feed in tariffs. http://ret.cleanenergyregulator.gov.au/Solar-Panels/ feed-in-tariffs. Accessed 1 Jul 2012

10. Frontier Economics (2012) Market value of solar PV exports: final report prepared for IPART. Frontier Economics Pty. Ltd., Melbourne

11. Martin J (2012) NSW Solar Bonus Scheme benchmark rate range to be 7.7c-12.9c for 2012-2013: IPART. http://www.solarchoice.net.au/blog/nswsolar-bonus-scheme-benchmark-rate-range-to-be-7-7c-12-9c-for-2012-2013ipart/. Accessed 1 Jul 2012

12. Independent Pricing and Regulatory Tribunal (2012) A fair and reasonable solar feed-in tariff for NSW. http://www.ipart.nsw.gov.au/Home/Industries/Electricity/ Reviews/Retail_Pricing/Solar_feed-in_tariffs___2012-2013. Accessed 30 Nov 2013

13. Kahneman D, Tversky A (1979) Prospect theory: an analysis of decision under risk. Econometrica 47(2):263-292

14. Fischer F (2000) Citizens, experts and the environment: the politics of local knowledge. Duke University Press, Durham NC, USA

15. Schusler TM, Decker DJ, Pfeffer MJ (2003) Social learning for collaborative natural resource management. Soc Nat Resour 16(4):309-326

16. Keen M, Brown V, Dyball R (2005) Social learning: a new approach to environmental management. In: Keen M, Brown VA, Dyball R (ed) Social learning in environmental management. Earthscan, London, pp 3-21

17. Webler T, Kastenholz H, Renn O (1995) Public participation in impact assessment: a social learning perspective. Environ Impact Asses 15(5):443-463

18. Collins H, Evans R (2007) Rethinking expertise. University of Chicago Press, Chicago

19. Collins H (2010) Tacit and explicit knowledge. University of Chicago Press, Chicago

20. Genennig B, Hoffman V (1995) Sociological accompanying study of the 1,000 roofs - PV programme initiated by the Federal as well as country government in Germany. In: 13th European photovoltaic solar energy conference. Nice, France, 23-27 Oct 1995

21. van Mierlo BC, Westra CA (1995) Attitude of occupants towards utility owned PV-sytems. In: 13th European photovoltaic solar energy conference. Nice, France, 23-27 Oct 1995

22. Oppenheim J (1995) A program to demonstrate that consumers place value on environmentally benign electricity: residential rooftop PV. In: 13th European photovoltaic solar energy conference. Nice, France, 23-27 Oct 1995

23. Sylvester KE (2000) An analysis of the benefits of photovoltaic-coated glazing on owning and operating costs of high rise commercial buildings. Dissertation Abstracts International Section A. Humanities and Social Sciences 2(1-A)

24. Blewett-Silcock T (2000) Public reaction to building integrated photovoltaics. In: 16th European photovoltaic solar energy conference. Glasgow, UK, 1-5 May 2000

25. Perez R, Burtis LA, Hoff T, Swanson S, Herig C (2004) Quantifying residential PV economics in the US payback vs. cash flow determination of fair energy value. Sol Energy 77:363-366

26. Riedy C (2003) Subsidies that encourage fossil fuel use in Australia. University of Technology, Sydney, Institute for Sustainable Futures

27. Wiginton LK, Nguyen HT, Pearce JM (2010) Quantifying rooftop solar photovoltaic potential for regional renewable energy policy. Comput Environ Urban 34(4):345-357

28. Mitchell C, Bauknecht D, Connor PM (2006) Effectiveness through risk reduction: a comparison of the renewable obligation in England and Wales and the feed-in system in Germany. Energ Policy 34:297-305

29. Lesser JA, Su X (2008) Design of an economically efficient feed-in tariff structure for renewable energy development. Energ Policy 36(3):981-990

30. Schaefer MS, Lloyd B, Stephenson JR (2012) The suitability of a feed-in tariff for wind energy in New Zealand - a study based on stakeholders' perspectives. Energ Policy 43:80-91

31. Maine T, Chapman P (2007) The value of solar: prices and output from distributed photovoltaic generation in South Australia. Energ Policy 35(1):461-466

32. Haas R, Ornetzeder M, Hametner K, Wroblewski A, Hübner M (1999) Socio-economic aspects of the Austrian 200 kWp-photovoltaic-rooftop programme. Sol Energy 66(3):183-191

33. Haas R (2002) An international evaluation of dissemination strategies for small grid-connected PV systems. In: World Renewable Energy Congress VII, Cologne, Germany, 29 June-5 July 2002 
34. Henry GT (1990) Practical sampling. In: Applied social research methods series, vol 21. Sage, Newbury Park

35. Bang HK, Ellinger AE, Hadjimarcou J, Traichal PA (2000) Consumer concern, knowledge, belief and attitude toward renewable energy: an application of the reasoned action theory. Psychol Mark 17(6):449-468

36. Hoyos D (2010) The state of the art of environmental valuation with discrete choice experiments. Ecol Econ 69:1595-1603

doi:10.1186/2192-0567-3-23

Cite this article as: Hampton and Eckermann: The promotion of

domestic grid-connected photovoltaic electricity production through social learning. Energy, Sustainability and Society 2013 3:23.

\section{Submit your manuscript to a SpringerOpen ${ }^{\circ}$} journal and benefit from:

- Convenient online submission

- Rigorous peer review

- Immediate publication on acceptance

- Open access: articles freely available online

- High visibility within the field

- Retaining the copyright to your article

Submit your next manuscript at $\gg$ springeropen.com 